\title{
Evaluasi Algoritma Wouthuyzen dan Son untuk Pendugaan Sea Surface Salinity (SSS) (Studi Kasus: Perairan Utara Pamekasan)
}

\author{
Nafizah $^{1}$, Lalu Muhamad Jaelani ${ }^{1}$ dan Gathot Winarso ${ }^{2}$ \\ ${ }^{1}$ Jurusan Teknik Geomatika, Fakultas Teknik Sipil dan Perencanaan, Institut Teknologi Sepuluh Nopember, \\ Kampus ITS Sukolilo, Surabaya 60111 Indonesia \\ e-mail:1mjaelani@geodesy.its.ac.id \\ ${ }^{2}$ Bidang Sumber Daya Wilayah Pesisir dan Laut, Pusat Pemanfaatan Penginderaan Jauh LAPAN \\ J1. Kalisari No.08 Pekayon Pasar Rebo, Jakarta 13710
}

\begin{abstract}
Abstrak- Pulau Madura merupakan pulau penghasil garam terbesar di Indonesia. Salah satu parameter yang digunakan dalam penentuan daerah potensi tambak garam adalah salinitas perairan (Sea Surface Salinity). Untuk memetakan persebaran salinitas perairan sebagai salah satu data pendukung dalam menganalisis potensi tambak garam dapat memanfaatkan citra satelit. Berbagai metode ekstraksi informasi salinitas perairan telah dikembangkan dan dimanfaatkan. Pengkajian pengukuran salinitas telah dilakukan dan menghasilkan algoritma salinitas perairan. Dalam penelitian ini, dilakukan evaluasi pada dua algoritma yang berbeda yaitu algoritma Wouthuyzen (2008) dan algoritma Son (2009) untuk melakukan estimasi nilai salinitas perairan di perairan utara Pamekasan, Madura. Sebelum dilakukan pemrosesan dengan algoritma, Citra Landsat-8 1T dikoreksi atmosfer dengan Second Simulation of a Satellite Signal in the Solar Spectrum-Vector (6SV). Hasil kajian ini menunjukkan bahwa perbedaan nilai salinitas perairan dari algoritma Wouthuyzen dengan data in-situ berkisar antara 2,66 hingga 3,91 psu. Sedangkan selisih salinitas algoritma Son dengan data in-situ 2,14 hingga 3,00 psu. Adapun nilai $N M A E$ algoritma Wouthuyzen dengan data in-situ sebesar $7,2 \%$, sedangkan pada algoritma Son sebesar $10,6 \%$.
\end{abstract}

Kata Kunci- Algoritma Son, Algoritma Wouthuyzen, Evaluasi, Salinitas Perairan

\section{PENDAHULUAN}

I NDONESIA merupakan negara maritim yang memiliki banyak potensi kelautan [1]. Salah satu potensi kelautan terbesarnya adalah tambak garam. Dengan garis pantai 81.000 $\mathrm{km}$ di Indonesia, lahan potensial untuk tambak garam seluas 34.000 hektar, baru dimanfaatkan seluas 18.000 hektar yang tersebar di seluruh wilayah Indonesia [2]. Berdasarkan perhitungan suplai kebutuhan, total kebutuhan garam Indonesia saat ini adalah 3,10 - 3,25 juta ton/ahun dengan perincian untuk garam konsumsi sekitar 1,20 - 1,45 juta ton/tahun dan garam industri sekitar 1,80 juta ton/tahun. Realitanya, kebutuhan nasional untuk garam, baik garam konsumsi maupun garam industri mengalami peningkatan setiap tahunnya [3]. Hal ini yang menyebabkan produktivitas garam Indonesia masih belum mencukupi kebutuhan masyarakat, sehingga Indonesia harus mengimpor garam untuk memenuhi kebutuhan tersebut [4].
Garam adalah suatu padatan berwarna putih berbentuk kristal yang merupakan kumpulan senyawa dengan bagian terbesar adalah Natruim Chlorida sebanyak $>80 \%$ serta senyawa lainnya yaitu Magnesium Chlorida, Magnesium Sulfat, Calsium Chlorida dan lain-lain dengan prosentase $<20 \%$ [5]. Dalam Effendi [6] disebutkan ketentuan jenis garam yaitu Garam konsumsi dan Garam industri. Garam konsumsi adalah garam yang dipergunakan untuk konsumsi dengan kadar $\mathrm{NaCl}$ paling sedikit 94,7\% dihitung dari basis kering. Sedangkan Garam industri adalah garam yang dipergunakan untuk konsumsi dengan kadar $\mathrm{NaCl}$ paling sedikit $97 \%$ dihitung dari basis kering.

Pulau Madura merupakan salah satu daerah penghasil garam terbesar di Indonesia [7]. Hampir 60\% produk garam nusantara dari Madura [2]. Luas wilayah tambak garam di pulau Madura mencapai 15.347 hektar. Namun, tingkat produktivitasnya masih lebih kecil dibandingkan rata-rata produktivitas nasional yang tercatat sebesar $70-100$ ton per hektar [8]. Salah satu faktor penyebabnya yaitu pemilihan lokasi eksplorasi. Untuk melakukan pengoptimalan hasil garam dilakukan pemetaan potensi. Pemetaan potensi tambak garam dilakukan dengan melakukan studi terhadap paramete rparameter untuk potensi tambak garam. Salah satu parameter untuk pemetaan tambak garam adalah salinitas air [9].

Penginderaan jauh (remote sensing) merupakan salah satu teknologi yang dapat digunakan untuk mengatasi masalah negara kepulauan, diantaranya batas wilayah, penentuan lokasi sumber daya alam, serta kemampuan dini dalam mendeteksi awalnya suatu bencana. Teknologi ini menggunakan kemampuan satelit yang dapat menangkap citra pemetaan suatu wilayah dengan spesifikasi yang dimilikinya. Salah satu sumber daya alam adalah tambak garam yang salah satunya dapat diperkirakan melalui parameter kelautan yaitu salinitas [10].

Salinitas perairan dapat dianalisis melalui teknologi penginderaan jauh. Son [11] melakukan pemetaan salinitas perairan didaerah teluk meksiko dengan menggunakan nilai $\mathrm{Lw}$ dan salinitas in-situ yang menghasilkan algoritma salinitas perairan. Wouthuyzen [12] memetakan sebaran salinitas permukaan Teluk Jakarta dan perairan di sekitarnya secara 
tidak langsung melalui penginderaan warna laut (konsentrasi CDOM) di Teluk Jakarta dengan citra Landsat-7 ETM.

Dalam penelitian ini, dilakukan evaluasi algoritma SSS (Sea Surface Salinity (SSS), Salinitas perairan) yaitu algoritma Wouthuyzen (2008) dan algoritma Son (2009) dengan data salinitas in-situ di perairan utara kabupaten Pamekasan yang diterapkan pada citra Landsat-8 tanggal 23 November 2015 daerah perairan sekitar Pulau Madura.

\section{A. Lokasi Penelitian}

Lokasi penelitian berada di Perairan utara Kabupaten Pamekasan, Madura.

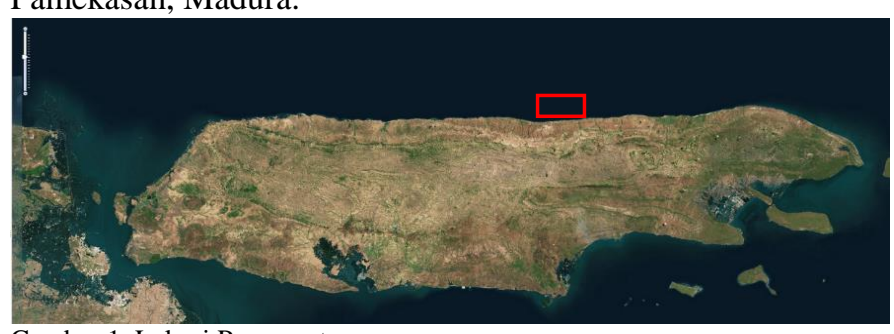

Gambar 1. Lokasi Pengamatan

\section{B. Pengumpulan Data In Situ}

Data in situ diambil di Perairan Kabupaten Pamekasan dengan elevasi stasiun pengamatan sekitar 10 meter. Data in situ yang diamati adalah salinitas perairan dengan menggunakan refractosalinometer dan koordinat lapangan menggunakan GPS Navigasi. Pengambilan data lapangan tersebar di 9 titik stasiun pengamatan pada tanggal 23 November 2015. Adapun sebaran stasiun pengamatan dapat dilihat pada tabel berikut.

Tabel 1.

Pengukuran Lapangan

\begin{tabular}{cccc}
\hline \hline Nama Titik & Lintang $\left({ }^{\circ}\right)$ & Bujur $\left(^{\circ}\right)$ & Salinitas $(\mathrm{psu})$ \\
\hline ST1 & $-6,878890$ & 113,529533 & 35 \\
ST2 & $-6,877260$ & 113,530067 & 35 \\
ST3 & $-6,875051$ & 113,537651 & 35 \\
ST4 & $-6,872846$ & 113,544426 & 35 \\
ST5 & $-6,868959$ & 113,561493 & 35 \\
ST6 & $-6,866741$ & 113,570702 & 35 \\
ST7 & $-6,874555$ & 113,579697 & 35 \\
ST8 & $-6,881670$ & 113,567261 & 35 \\
ST9 & $-6,887170$ & 113,552910 & 34 \\
\hline \hline
\end{tabular}

\section{Citra Landsat 8}

Citra yang digunakan pada penelitian ini adalah citra Landsat 8-L1T di sekitar perairan Pulau Madura tanggal 23 November 2015. Jenis data ini tersedia secara gratis dan dapat dipesan melalui http:/earthexplorer.usgs.gov/.

\section{Pengolahan Data}

Hal pertama yang dilakukan dalam pengolahan data adalah koreksi radiometrik citra. Koreksi radiometrik, proses ini terbagi menjadi dua yaitu kalibrasi radiometrik dan koreksi atmosfer. Kalibrasi radiometrik bertujuan merubah $D N$ (Digital number) ke radian ToA (Top of Atmospheric) atau reflektan menggunakan parameter yang tersedia di metadata citra. Koreksi atmosfer merupakan koreksi yang dilakukan untuk menghapus efek atmosfer dari sinyal yang direkam oleh sensor.
Koreksi atmosfer dilakukan dengan cara mengkonversi nilai radian ToA (Top of Atmospheric) ke nilai reflektan BoA (Bottom of Atmospheric).

Citra Landsat 8 Level 1T merupakan data mentah yang berformat Digital Number (DN). Kalibrasi radiometrik dilakukan dengan menggunakan parameter Gain dan Offset yang tersedia dalam metadata citra Landsat 8 .

$$
\mathrm{L}_{\lambda}=\mathrm{M}_{\mathrm{L}} \mathrm{Q}_{\mathrm{cal}}+\mathrm{A}_{\mathrm{L}}
$$

dimana,

$$
\begin{aligned}
& \mathrm{L}_{\lambda}=\text { TOA spectral radiance }\left(\mathrm{W}\left(\mathrm{m}^{2} \operatorname{srad} \mu \mathrm{m}\right)^{-1}\right) \\
& \mathrm{M}_{\mathrm{L}}=\text { Radiance Mult Band } \\
& \mathrm{A}_{\mathrm{L}}=\text { Radiance Add Band } \\
& \mathrm{Q}_{\text {cal }}=\text { Digital Number }(\text { DN }) \text { Band }
\end{aligned}
$$

Selanjutnya dilakukan koreksi atmosfer dengan menggunakan metode Second Simulation of a Satellite Signal in the Solar Spectrum-Vector (6SV). Koreksi citra dengan metode $6 S$ diawali dengan pengambilan nilai parameter $x_{a}, x_{b}$, dan $x_{c}$. yang dilakukan melalui situs resmi $6 S$ yaitu www.6s.ltdri.org [13]. Koneksi internet yang baik, sangat mendukung dalam menjalankan situs ini. Beberapa parameter yang harus dimasukkan dalam tiap langkah saat menjalankan situs antara lain identifikasi kondisi geometri, deskripsi model atmosfer, kondisi spektral, parameter polarisasi permukaan, jenis objek, dan deskripsi elevasi objek.

Parameter $x_{a}, x_{b}$, dan $x_{c}$ dari situs www.6s.ltdri.org didapatkan sebagai berikut.

Tabel 2. Parameter $6 S$

\begin{tabular}{lccc}
\hline \hline \multicolumn{1}{c}{ Parameter 6S } & Xa & Xb & Xc \\
\hline Kanal 1 & 0,00253 & 0,16047 & 0,22274 \\
Kanal 2 & 0,00226 & 0,11662 & 0,18791 \\
Kanal 3 & 0,00236 & 0,07078 & 0,14093 \\
Kanal 4 & 0,00259 & 0,04712 & 0,11199 \\
Kanal 5 & 0,00382 & 0,02903 & 0,08446 \\
\hline \hline
\end{tabular}

Parameter tersebut kemudian dimasukkan kedalam rumus (3), (4) dan (5) untuk didapatkan nilai $\operatorname{Rrs}(\lambda)$.

Adapun persamaan koreksi Second Simulation of a Satellite Signal in the Solar Spectrum-Vector (6SV), sebagai berikut:

$$
\begin{aligned}
& \mathrm{Y}=\left(\mathrm{X}_{\mathrm{a}} \mathrm{L}_{\lambda}\right)-\mathrm{X}_{\mathrm{b}} \\
& \operatorname{arc}=\frac{\mathrm{Y}}{\left(1 .+\mathrm{X}_{\mathrm{c}} \mathrm{Y}\right)} \\
& \operatorname{Rrs}(\lambda)=\frac{\operatorname{arc}}{\pi}
\end{aligned}
$$

dimana, acr adalah atmospheric correction reflectance, $\mathrm{L}_{\lambda}$ adalah nilai radian $T O A, R \operatorname{rs}(\lambda)$ adalah reflektan permukaan, dan $X_{\mathrm{a}}, X_{\mathrm{b}}, \mathrm{X}_{\mathrm{c}}$ adalah koefisien parameter koreksi atmosfer.

Setelah dilakukan koreksi atmosfer, data dari 9 stasiun pengamatan diekstrak berdasarkan pin yang telah dibuat (disesuaikan dengan koordinat data lapangan). Semua pemrosesan citra dalam penelitian ini dilakukan dengan menggunakan perangkat lunak open source SNAP 2.0 Toolbox. 
Nilai reflektan citra yang telah terkoreksi atmosfer dan data salinitas perairan in situ diproses dengan algoritma eksisiting untuk mendapatkan nilai estimasi salinitas perairan.

Adapun algoritma eksisting salinitas perairan yang digunakan pada penelitian ini yaitu Wouthuyzen (2008) dan Son (2009) masing-masing sebagai berikut.

\section{Konsentrasi CDOM}

$=(-61,182 \times \mathrm{X} 3+79,129 \times \mathrm{X} 2+34,022 \times \mathrm{X}+4,885)$

Salinitas $(\mathrm{psu})=-142,72 \times$ Konsentrasi CDOM $+32,702$

dimana X merupakan kromatisiti biru yaitu $\operatorname{Rrs}(\lambda 2) /(\operatorname{Rrs}(\lambda 2))+$ $\operatorname{Rrs}(\lambda 3)+\operatorname{Rrs}(\lambda 4)$ dari Landsat 8.

Algoritma Son (2009) sebagai berikut.

${ }_{\mathrm{MNDCI}}=\frac{[L w(555)-L w(490)]}{[L w(555)+L w(490)]}$

$C_{\mathrm{p}}=10^{\left[0,70 \times \mathrm{MNDCI}^{3}+0,96 \times \mathrm{MNDCI}^{2}+1,14 \times \mathrm{MNDCI}-0,25\right]}$

Salinitas $(p s u)=10^{\left[-0,141 \times \log _{10}\left(C_{p}\right)+1,45\right]}$

Setelah melakukan pengolahan menggunakan algoritma Wouthuyzen (2008) dan Son (2009) didapatkan hasil estimasi konsentrasi saliniats perairan di sekitar Pulau Madura.

\section{E. Pengujian Akurasi}

Untuk menguji akurasi data pengukuran dan data estimasi dari citra, digunakan indeks Normalized Mean Absolute Error (NMAE).

$\operatorname{NMAE}(100 \%)=\frac{1}{N} \sum\left|\frac{x \text { esti }-x \text { meas }}{x \text { meas }}\right| \times 100$

Dimana NMAE adalah Normalized Mean Absolute Error, $\mathrm{N}$ mewakili jumlah data, Xesti adlah nilai hasil pengolahan dan Xmeas adalah nilai hasil pengukuran lapangan yang dianggap benar.

\section{HASIL DAN ANALISA}

\section{A. Hasil koreksi radiometrik citra}

Setelah dilakukan kalibrasi radiometrik dengan parameter Gain dan Offset dan koreksi atmosfer dengan metode $6 S$. Dihasilkan nilai $R \mathrm{rs}_{(\lambda)}$ seperti pada grafik berikut.

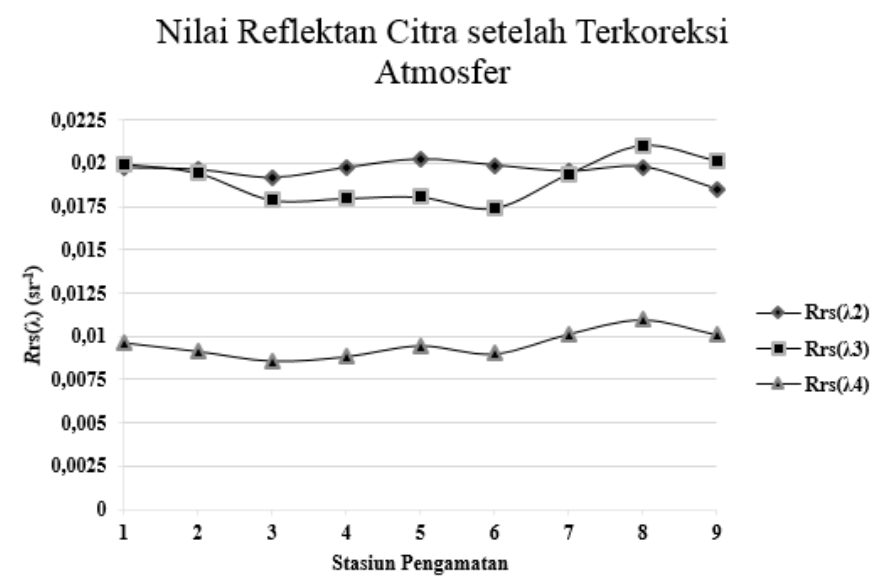

Gambar 2. Grafik Nilai Reflektan Citra setelah terkoreksi atmosfer

Dari grafik tersebut dapat diihat bahwa nilai reflektan Landsat 8 tanggal 23 November 2015 setelah terkoreksi atmosfer menunjukkan nilai $\operatorname{Rrs}_{(\lambda 2)}$ dan $\operatorname{Rrs}_{\left(\lambda_{3}\right)}$ memiliki nilai yang lebih besar daripada $\operatorname{Rrs}(\lambda 3)$.

\section{B. Estimasi Salinitas Perairan}

Citra yang telah terkoreksi atmosfer kemudian dilakukan pemrosesan dengan algoritma eksisiting. Adapun hasil estimasi salinitas perairan adalah sebagai berikut.

$$
\text { Tabel } 3 .
$$

Hasil Estimasi Salinitas dari Algoritma Eksisting

\begin{tabular}{cccc}
\hline \hline & \multicolumn{3}{c}{ Salinitas Perairan $(p s u)$} \\
\cline { 2 - 4 } Stasiun & $\begin{array}{c}\text { Estimasi } \\
\text { Wouthuyzen }\end{array}$ & $\begin{array}{c}\text { Estimasi } \\
\text { Son }\end{array}$ & In-situ \\
\hline ST1 & 32,53 & 32,33 & 35 \\
ST2 & 32,58 & 31,09 & 35 \\
ST3 & 32,52 & 31,32 & 35 \\
ST4 & 32,48 & 31,40 & 35 \\
ST5 & 32,48 & 31,48 & 35 \\
ST6 & 32,41 & 31,54 & 35 \\
ST7 & 32,51 & 31,09 & 35 \\
ST8 & 32,00 & 30,81 & 35 \\
ST9 & 31,86 & 30,72 & 34 \\
\hline \hline
\end{tabular}

Berdasarkan nilai estimasi yang didapat, nilai salinitas estimasi pada stasiun pengamatan ST1 menunjukkan nilai 32,53 psu pada algoritma Wouthuyzen dan 32,33 psu pada algoritma Son. Sedangkan stasiun pengamatan yang lain dari ST2 hingga ST9 masing-masing untuk algoritma Wouthuyzen antara lain 32,58 psu, 32,52 psu, 32,48 psu, 32,48 psu, 32,41 psu, 32,51 psu, 32,00 psu dan 31,86 psu. Untuk pengamatan dari ST2 hingga ST9 masing-masing untuk algoritma Son antara lain 32,33 psu, 31,09 psu, 31,32 psu, 31,40 psu, 31,48 psu, 31,54 psu, 32,51 psu, 32,00 psu dan 31, psu psu.

Adapun selisih nilai estimasi salinitas dari algoritma Wouthuyzen pada ST1 hingga ST9 antara lain 2,66; 3,91; 3,68; 3,$60 ; 3,52 ; 3,46 ; 3,91 ; 4,18$ dan 3,28 psu. Adapun selisih terbesar berada pada stasiun ST2 dan ST8 yaitu 3,91 psu. Sedangkan selisih terkecil berada pada stasiun ST1 yaitu 2,66 psu.

Selisih nilai estimasi salinitas dari algoritma Son pada ST1 hingga ST9 antara lain 2,47; 2,42; 2,48; 2,52; 2,52, 2,59; 2,49; 3,00 dan 2,14 psu. Adapun selisih terbesar berada pada stasiun ST8 yaitu 3,00 psu dan selisih terkecil pada stasiun ST9 yaitu 2,14 psu u. 


\section{Uji Akurasi}

Nilai salinitas estimasi dari algoritma eksisting kemudian diuji dengan menggunakan nilai $N M A E$. Adapun nilai $N M A E$ salinitas estimasi menggunakan algoritma Wouthuyzen dan salinitas in-situ terlihat pada grafik berikut.

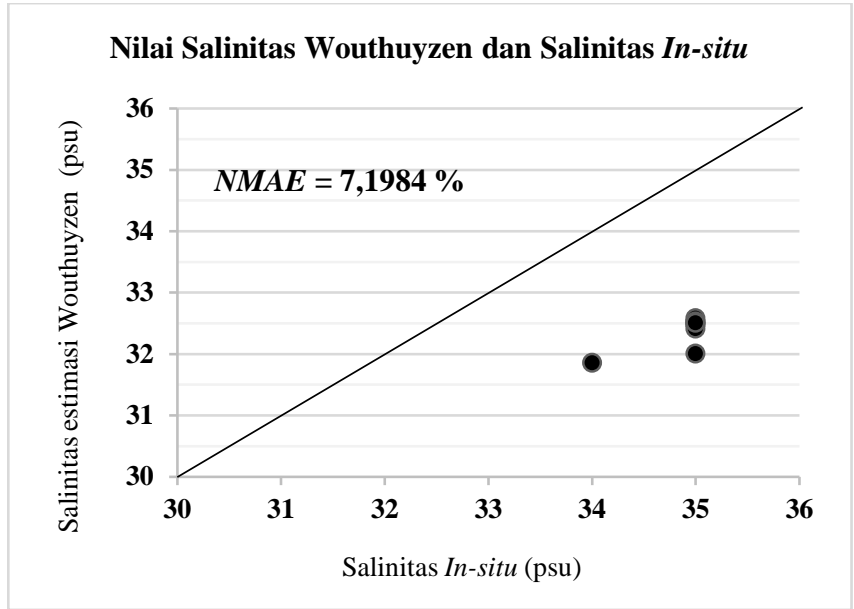

Gambar 3. Grafik nilai salinitas Wouthuyzen dan salinitas in-situ

Berikut adalah grafik hubungan nilai estimasi dari algoritma Son dan salinitas in-situ.

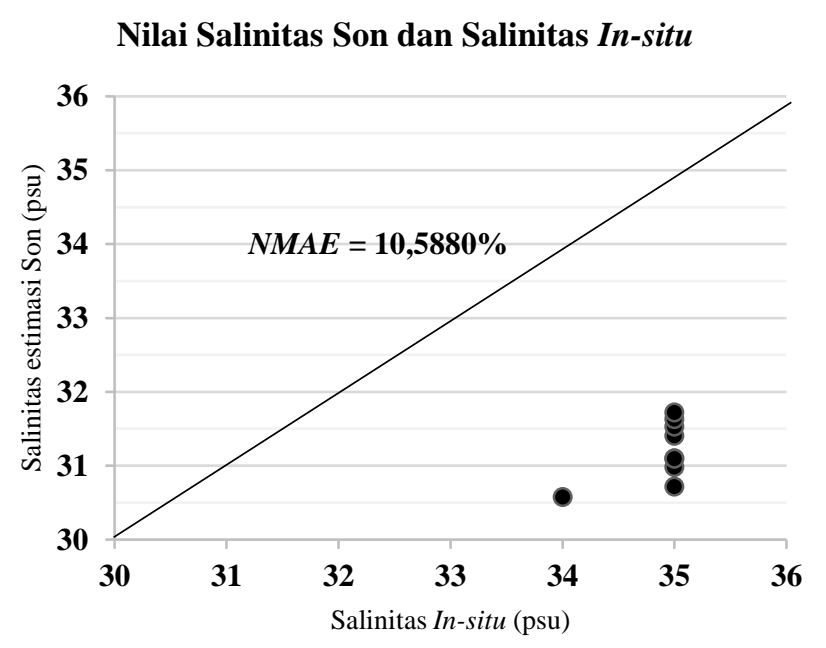

Gambar 4. Grafik hubungan nilai salinitas Son dan salinitas in-situ

Dari dua grafik hubungan salinitas estimasi esksisting dan insitu menghasilkan nilai NMAE $7,2 \%$ pada algoritma Wouthuyzen dan $10,6 \%$ pada algoritma Son. Berdasarkan nilai NMAE, kedua algoritma eksisiting menunjukkan hubungan yang baik antara nilai estimasi dan nilai in-situ karena memenuhi persyarakatan nilai $N M A E$ yaitu kurang dari $30 \%$. Semakin kecil nilai $N M A E$ maka hubungan antar datanya semakin baik.

Namun, algoritma salinitas perairan dari Wouthuyzen dibangun dengan tidak menggunakan data reflektansi permukaan lapangan melainkan ekstraksi dari SR-USGS sehingga pengaruh atmosfernya belum hilang. Koreksi atmosfer yang akurat merupakan syarat utama dalam melakukan estimasi parameter kualitas air. Kesalahan dalam proses koreksi atmosfer ini akan menjalar ke algoritma model yang digunakan untuk menghitung parameter kualitas air. Padahal untuk melakukan ekstraksi data, akurasi parameter tersebut tidak hanya dipengaruhi oleh algoritma model tetapi juga algoritma koreksi atmosfer. Kesalahan yang terjadi kemudian merambat pada kesalahan proses selanjutnya. Berdasarkan Jaelani [13] akurasi produk SR-USGS sebesar 59\% sehingga masih belum cukup memadai untuk bisa digunakan secara langusng. Sedangkan, algoritma Son dibuat dengan menggunakan nilai spektral lapangan yaitu $L w$. Sehingga dapat disimpulkan bahwa akurasi yang lebih tinggi dari salinitas Wouthuyzen tidak murni dihasilkan algoritma modelnya.

Sebaran salinitas perairan Madura dengan menggunakan algoritma Wouthuyzen dan Son sebagai berikut.

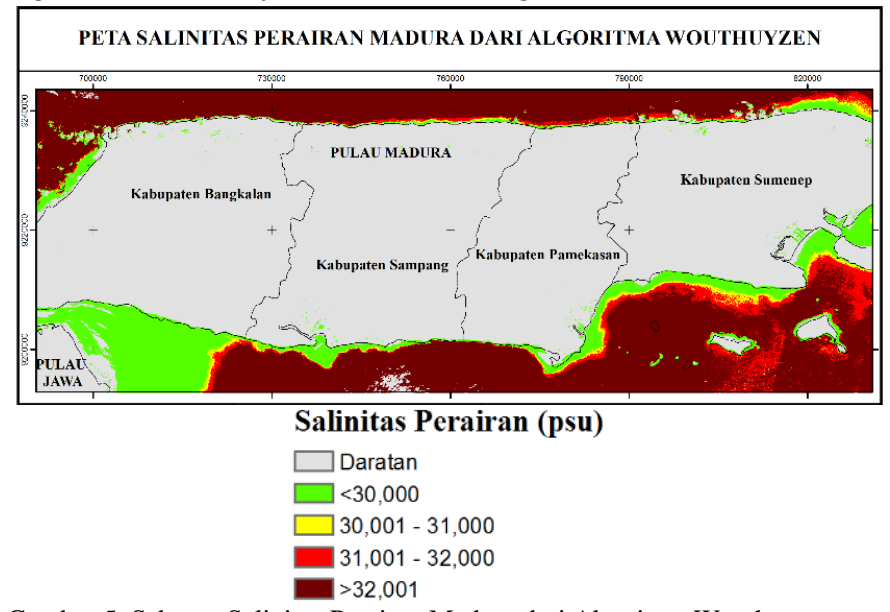

Gambar 5. Sebaran Salinitas Perairan Madura dari Algoritma Wouthuyzen

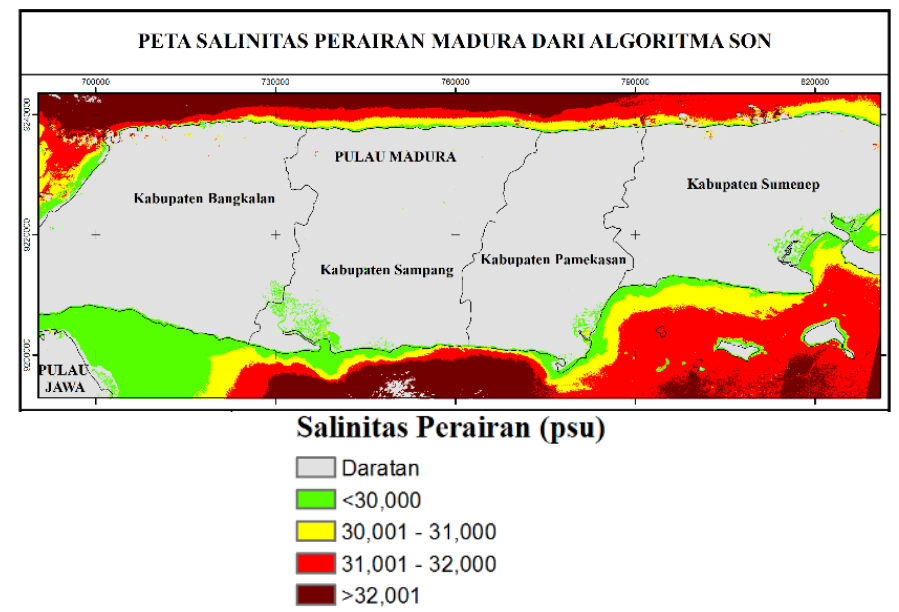

Gambar 6 Sebaran Salinitas Perairan Madura dari Algoritma Son

Gambar 5 dan 6 menunjukkan adanya perbedaan nilai salinitas antara algoritma wouthuyzen dan Son. Salinitas dengan menggunakan algoritma wouthuyzen memiliki nilai yang lebih tinggi daripada salinitas dengan menggunakan algoritma Son. Adanya perbedaan gradasi salinitas pada tiap peta menunjukkan perbedaan nilai antara keduanya.

\section{KESIMPULAN DAN SARAN}

Evaluasi algoritma salinitas perairan dari algoritma 
Wouthuyzen dengan data in-situ menghasilkan salinitas perairan dengan perbedaan berkisar antara 2,66 hingga 3,91 psu. Sedangkan selisih salinitas algoritma Son dengan data insitu berkisar antara 2,14 hingga 3,00 psu. Adapun nilai NMAE algoritma Wouthuyzen dengan data in-situ sebesar 7,2 \%, sedangkan pada algoritma Son sebesar 10,6 \%. Semakin kecil nilai NMAE maka hubungan antar datanya semakin baik. Nilai NMAE algoritma Wouthouyzen lebih baik dari algoritma Son, namun algoritma Wouthuyzen dibangun bukan dari nilai spektral lapangan. Sehingga, untuk ekstraksi nilai salinitas perairan lebih baik menggunakan algoritma Son karena algoritmanya dibangun dai nilai radian lapangan dan memiliki nilai NMAE yang memenuhi syarat $<30 \%$.

\section{DAFTAR PUSTAKA}

[1] Kementrian Kelautan dan Perikanan Republik Indonesia. Keanekaragaman Hayati Laut Indonesia. 20 September 2015. http://kkp.go.id.

[2] Fiqiani, Rika Rachmi. 2013. "Garam Madura : Antara Eksotisme dan Peluang." SURAMADU Membangun dengan Hati (Edisi 7), Oktober 2013: Halaman 34.

[3] Meissarah, P dkk. 2013. Pemetaan Lahan Garam Bali, Nusa Tenggara Barat, Nusa Tenggara Timur dan Sulawesi Selatan. Cibinong: Pusat Pemetaan dan Integrasi Tematik - Deputi IGT, BIG.

[4] Bakosurtanal. 2010. Peta Lahan Garam Indonesia. Halaman 1-5. Cibinong: Pusat Survei Sumber Daya Alam Laut Badan Koordinasi Survei dan Pemetaan Nasional.

[5] Sungkowo, W.B. 2006. "Perdagangan Garam di Indonesia." Disampaikan dalam seminar sehari "Mencari Alternatif Pengembangan Industri Garam dan Produk Terkait Lainnya”. Badan Riset Kelautan, Departemen Kelautan dan Perikanan Republik Indonesia.

[6] Effendi, H. 2003. Telaah Kualitas Air. Bagi Pengelolaan Sumber daya dan Lingkungan Perairan. Kanisius. Yogyakarta. 258 hal.

[7] Departemen Kelautan dan Perikanan Republik Indonesia. 2006. Standar Kualitas Garam Dan Produk Turunannya. Disampaikan dalam seminar sehari "Mencari Alternatif Pengembangan Industri Garam dan Produk Terkait Lainnya”. Badan Riset Kelautam, Departemen Kelautan dan Perikanan RI

[8] Badan Perencanaan dan Pembangunan Sampang. 2011. Laporan Akhir Masterplan Revitalisasi Tambak Kabupaten Sampang. Sampang: Pemerintah Kabupaten Sampang.

[9] Badan Informasi Geospasial. 2012. Standart Operating Procedure No.03.01.23 Tentang Pemetaan Tambak Garam. Pusat Pemetaan dan Integrasi Tematik Badan Informasi Geospasial (PPIT-BIG).

[10] Annas, Rifqy. 2009. Pemanfaatan Data Satelit MODIS untuk Menentukan Suhu Permukaan Laut. Depok: Program Studi Elektro Fakultas Teknik Universitas Indonesia.

[11] Son, BY, Wilford DG, Mary J R, Joji I, Joo H R, Sang H K dan Sang H L. 2011. Tracing Offshore Low-Salinity Plumes in the Northeastern Gulf of Mexicoduring The Summer Season by Use of Multispectral Remote Sensing data. Journal of Oceanograpphy edited by The Oceanographic Society of Japan ISSN 0916-8370 Volume 68 Number 5.

[12] Wouthuyzen, Sam. Salam Tarigan, Happy Indarto Supriyadi, Agus Sediadi, Sugarin, Vincentius P. Siregar dan Joji Ishizaka. Pengukuran Salinitas Permukaan Teluk Jakarta Melalui Penginderaan Warna Laut Menggunakan Data Multi-Temporal Citra Satelit Landsat-7 ETM+. PIT MAPIN XVII, Bandung 10-12-2008

[13] Jaelani, Lalu muhamad, dkk. 2015. Uji Akurasi Produk ReflektanPermukaan Landsat Menggunakan Data In Situ di Danau Kasumigaura, Jepang. Prosiding Pertemuan Ilmiah Tahunan Masyarakat Ahli Penginderaan Jauh Indonesia XX. Bogor 